\title{
Purine nucleoside phosphorylase deficiency
}

INSERM

\section{Source}

INSERM. (1999). Orphanet: an online rare disease and orphan drug data base. $\underline{\text { Purine }}$ nucleoside phosphorylase deficiency. ORPHA:760

Purine nucleoside phosphorylase (PNP) deficiency is a disorder of purine metabolism characterized by progressive immunodeficiency leading to recurrent and opportunistic infections, autoimmunity and malignancy as well as neurologic manifestations. 